\title{
HUMANISING DATA THROUGH SOUND: RES EXTENSAE AND A USER-CENTRIC APPROACH TO DATA SONIFICATION
}

\author{
Sara Lenzi
}

\author{
Density Design Lab, Design Department, \\ Politecnico di Milano \\ Via G. Candiani, 72 \\ 2058 Milano, Italy \\ sara.lenzi@polimi.it
}

\begin{abstract}
In this paper, starting from a case study (the mixed-media data sonification installation Res Extensae), we discuss a number of assumptions on the efficacy of sound as a means to represent and communicate numerical data. The discussion is supported by the results of a questionnaire aimed at validating our assumptions and conducted with fifteen of the participants to the experience. At the same time, we have the ambition to contribute to a wider debate on the value of data sonification. We introduce the first stage of a research on sonification as a design-driven, user-centred and multi-modal experience, in that closer to data design practices rather than to traditional composition and computer music. We describe the usage of physical objects to help users to put sounds and data into a wider context, improving the user experience and facilitating the comprehension and retention of the meaning of data.
\end{abstract}

\section{INTRODUCTION}

Res Extensae is a data sonification art installation premiered in Trento, Italy, in September 2017, and sponsored by the European Union (EU) program INTERREG Europe OSIRIS. The goal of the project was that of raising awareness, through art, on the (sometimes unexpected) possibilities of re-usage of open data from the public administration, in the framework of the EU vision of a Digital Single Market and uniformed Open Data policy within the Union. ${ }^{1}$

The ambition of the project matched well the author's belief, sustained, as we will see shortly, by a current debate among the experts in the emerging necessity of humanising the approach to data design in order to counterbalance data overload in the untrained, non-expert user. In the case here presented, the use of sonification as the main means of representing the chosen data sets aims to investigate the role of the auditory sensory dimension in engaging with structured, quantitative information at the emotional level. In an effort of experimenting with different modalities to measure the efficacy of sound both alone and combined with other modes of interaction, Res Extensae was designed as a multi-modal installation where sound elements are combined with found

${ }^{1}$ Samples of the project can be listened to online at https://soundcloud.com/user-467084838/sets/res-extensae-adata

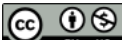

cc. This work is licensed under Creative Commons

Attribution - Non Commercial 4.0 International License.

The full terms of the License are available at

http://creativecommons.org/licenses/by-nc/4.0/

\author{
Francesca Gleria
}

\author{
Servizio Supporto alla Direzione Generale e ICT, \\ Provincia Autonoma di Trento \\ Piazza Dante, 15 \\ 38122, Trento, Italy \\ francesca.gleria@provincia.tn.it
}

objects and displayed in the exhibition space as a full rounded, physical in situ experience.

This is part of a long-term investigation on the potentialities and possibilities of a user-centred, multi-modal framework for data design.

\subsection{Communicating Public Data in the European Union: Opening Silos}

Starting from the year 2011, The European Union Commission has issued a series of Communications (a policy document with no mandatory authority) defining the 2020 strategy for a sustainable growth path inside the Union, focussing (among other goals) on the untapped potential of the re-use of public data. Public data are defined by the Commission as all the information that public bodies in the European Union produce, collect or pay for [1]. Behind the public advocacy of data re-use lies a wider and stronger need of fostering data culture inside the public sector. In an age where public administrations in Europe are facing several challenges [2], from structural and organisational changes to budget reductions and a decreasing political legitimacy, the EU policy makers openly advocate for the dissemination and re-use of public data with the final goals of increasing its economic value, foster innovation, improve transparency, and engage citizens. Digital data are, in fact, a rather unique type of raw material, one that is not consumed by usage. Quite the opposite, the more data are used, inside and outside the borders of their original domain, the more they become valuable [3].

While the main economic effort of the EU and its Members Countries is focussed on helping local public administration in the transition to the Digital Single Market [4] (harmonising data collection, storage and accessibility) the accent of the public discourse [5] goes on the need to break "data silos" crossing borders inside and outside the public administration. Public administrations are encouraged to learn to speak different languages to increase data value awareness among the public. In a user-centric vision of the data life cycle, there is a strong need to engage citizens in order to give back to them the data they contributed to create ${ }^{2}$.

\subsection{Humanising Data}

In recent years, as an attitude that can be defined "data culture" is progressively emerging, the practice of translating large sets of discreet (mostly numerical) information into a

\footnotetext{
${ }^{2}$ Paraphrasing http://uciad.info/ub/2012/02/uciad-the-secondphase/index.html (Last access 10th May 2017)
} 
more efficient means of understanding has reached momentum. Data are, though, much more that an objective series of numerical values. Confronted with a data set, in the effort to make sense of it we will gather a wider picture which includes broader associations between the data and other relevant background knowledge we may have including "any previous knowledge and expectations" which will inevitably condition the way we connect to the data. [6]

Data Design practices are today at the centre of a crossdisciplinary public debate and emerging activism, involving mostly designers, artists, journalists, data philanthropists. In December 2016, Google News Lab launched an extensive data visualisation project to "tell stories with Google Data" [7]. With the words of Simon Rogers, Google News Lab data editor, the goal of the project is to "communicate ideas" [8] giving back to users their own data within a context, in a statement that echoes the European Union vision of a circular data economy with citizens at the centre.

The data journalist Jacob Harris shared a similar perspective in 2015 [9] when he openly advocated for an "empathic design" in data representation, able to engage the readers at the human level. Inside academia, in 2007 Cawthon and Vande Moere run an experiment to investigate the relationship between aesthetic beauty and usability in data visualisation. They explicitly quoted Donald Norman [10] in theorising that the affection developed by users towards an aesthetically beautiful data visualisation encourages them to think creatively in order to solve any problem or in general to explore more efficiently and effectively the information presented [11].

Given the huge quantity of data now out in the public debate, mainstream data design disciplines (such as data visualisation) are seeking new ways of representing data to engage the public at a more visceral [10] (or "human") level in an effort of raising awareness on the importance of data for the current and future society. Recent examples of this trend include "data cuisine" [12], "data pottery" [13] and "data sculpture" [14]. Among this emerging trans-disciplinary practice, data visualisation experts are timidly starting to recognise the potentialities of sound and music as an effective way of communicating emotional connotations of information, through qualities such as tempo, volume, or timbre [15].

\subsection{Sonification in a multi-modal context}

Traditionally, Data Sonification has been understood as a tool for the representation of scientific data through computer generated sounds [16]. Despite being an academic subject of research since the 1990s, "While visual rendering (visualisation) has become an everyday affair, the representation of data or information by sound remains much less common." [16] Sonification is still, disappointingly, a relatively isolated field let aside the occasional pseudosensational article on "eerie sound of Saturn"3.

A number of hypothesis can be made why sound remains an under-represented, under-used means of conveying information, while there seem to be no theoretical aversion in the design community to that sound "when used properly, is both emotionally satisfying and informationally rich" [10]. Factors such as absence of a friendly audio technology both

${ }^{3}$ https://www.sciencealert.com/nasa-has-recorded-the-firstsounds-of-the-eerie-void-inside-saturn-s-rings during the usage of sonification [17] and during the presentation of results to the peer community [18]; prevalence of visual language in the Western cultural landscape over the centuries [16]; arbitrary mapping of data to sound parameters without a "natural" connection between data and sound [19]; and lack of education in interpreting auditory stimuli among scientists [17], are among the most quoted.

More in general, sonification has been traditionally presented to the public with a lack of a real life, physical context that the acousmatic experience (as Pierre Schaeffer defines it, an experience based on "Sounds one hears without seeing their originating cause" [20]) usually entails. This aspect, together with the lack of education in integrating abstract, non-speech sounds into our everyday experience (something that happens on a daily basis with non-physical, digital visual elements [21]) might be another reason why sonification has not managed to become a relevant tool in information communication. The lack of focus on the listening experience (in favour of a focus on the sonification process), underestimates the "wider sonic space" [6] that nevertheless the recipient of the sonification (be her a scientist, a researcher, a visitor of an art exhibition) will intuitively refer to, to decode the relationship between sonic parameters and data. We propose to turn outside the world of sound programming and computer music, in search of other fields where sound is successfully used as embodied in a multi-dimensional, cross-modal context and widely accepted as a valuable, sometimes even necessary element of the user experience.

In the history of sonification, the Geiger-counter is possibly the most quoted [22] and the most successful example of using sound to monitor and alert users, and the one stuck into the collective memory. But more recently multimodal design research has shown a renewed interest in leveraging sound specificities, drawn mainly from psychology and psychoacoustics, cognitive sciences and neurosciences [15], to design more efficient user experiences in order to increase the information bandwidth and avoid information overload in Virtual Reality (VR) highly complex environments [17]. Maybe surprisingly, in these contexts not only functionality and efficiency but also the aesthetic of sound appears as an increasingly important characteristic to make auditory feedbacks more relevant and easier to interpret [37]. VR training and research environments in scientific disciplines could highly benefit of positional audio and dynamic soundscapes synthesis common to video games to create an immersive environment. Immersive soundscapes could be used by a user to constantly monitor the overall status of a system, while freeing the visual channel for other, simultaneous precise tasks [17].

Cinematography is another field where sound is used, quite fruitfully, to efficiently convey relevant (sometimes fundamental) information on the development of the narrative in the context of a multi-modal experience. Despite cinema not being, undeniably, a data design process, it is nonetheless a field where sound is widely accepted as an extremely successful and necessary means of communicating information, and therefore we believe it deserves our attention in the context of the present work.

\subsection{Three converging perspectives}

The project that we will be describing in detail in the coming sections is, to sum it up, the resultant of three converging perspectives on data: 
- We need to engage citizens on the importance of public data and the intrinsic value of the re-use of data produced by the public administration.

- There is a growing quest for a design approach able to foster a more "human" relationship with data representation for a better user experience.

- Sound is widely recognised in a number of disciplines, ranging from art to interface and product design through branding, as an efficient means of communicating information and emotion at the same time. Sonification based on acousmatic sounds is still sometimes met with a skeptical mind by the scientific community [23]. We will be looking at overcoming this aspect integrating sound into a full rounded experience in order to test the potentiality of a multi-modal, contextualised, embodied approach to data sonification.

\section{RES EXTENSAE: A MULTI-MODAL SONIFICATION EXPERIENCE}

INTERREG Europe OSIRIS is a European Union project dedicated to Open Social Innovation policies driven by cocreative Regional Innovation ecosystems [24]. Started in 2016, OSIRIS was born in the frame of the EU policies and activities aimed at facing increasing social challenges in the Union, as outlined in the introduction to this paper. Seven public bodies from seven different regions in Europe (Vasterbotten,Sweden ; Ostrobothnia, Finland; Provincia Autonoma di Trento, Italy; Drenthe Province, Netherland; Computer Institute and Press Diophantus, Greece;Abo Akademi University, Finland; Fundao Municipality, Portugal; Regional Development of Presov Region, Slovakia) share good practices to foster innovation in the field of employment, education, social inclusion and climate/energy with the objective of implementing cross-borders smart solutions and disseminating improvements.

The goal of the program is to increase the efficacy of local policies for a better use of the EU structural funds. In particular, the OSIRIS project aims to do that within the framework of a co-creative approach sharing best practices among the partners. In September 2017, an OSIRIS meeting was held in the partner region of Provincia Autonoma di Trento, an autonomous region in the north of Italy. The three days of activities, titled "Data Driven Innovation and Territorial Growth" focussed on the discussion about data (mostly open local governments data) presenting ways to enable data driven economies and open social innovation and facilitating networking between public administrations as data provider and private companies (as potential data buyers).

\subsection{Background}

In the context of the meeting, OSIRIS commissioned to $\mathrm{xxx}$ an artistic work with the objective of raising awareness on the reusability of open data sets from the public administration among its member regions and their related citizen networks. The project, which took the shape of a multi-modal, mixedmedia installation, was experienced by the public in the outdoor courtyard of Palazzo Roccabruna, in the Italian City of Trento. This section will describe the decisions taken by the author during the conceptualisation of the work, later called "Res Extensae". The title is an homage to the philosopher of the XVI century Rene Descartes and his well-known investigation of the relationship between body and mind (res extensa and res cogitans, respectively). We are today facing a new dualism, between an extended body of digital data and our human-scaled minds. On one side, quantitative information is continuously collected that tracks and describes our everyday life and the world around us. On the other side, this extended body is coupled by our limited cognitive capacities that, at the other extreme of the Descartes dualism, both collectively and intimately, try to grasp the extension and attribute meaning to these large collections of numbers. The artistic experience is seen, in this case, as a means to overcome our limits and make numerical data closer to the human scale.

\subsection{Choice of Data Sets}

The data sets were freely chosen by the author from the online open repository of the Autonomous Province of Trento, the Trentino Open Data web portal. Several considerations were made in order to choose, mostly related to the unique characteristics of the location were the installation was to be performed, in the historical centre of the city of Trento. The Trentino region is, in fact, cut in the middle by the second most important river of Italy, the River Adige. The River shaped the historical town in her early days, before its course being deviated in the nineteenth century by the Austrian Empire's engineers.

Nowadays, the river is constantly monitored with a system of sensors which collect, every fifteen minutes, inputs on the river height (hydrometer), flow rate, rain rate (hygrometer) and temperature. The measurement is taken at each station along the course of the river in the Trentino territory, and released for open use from the portal in the form of a spreadsheet.

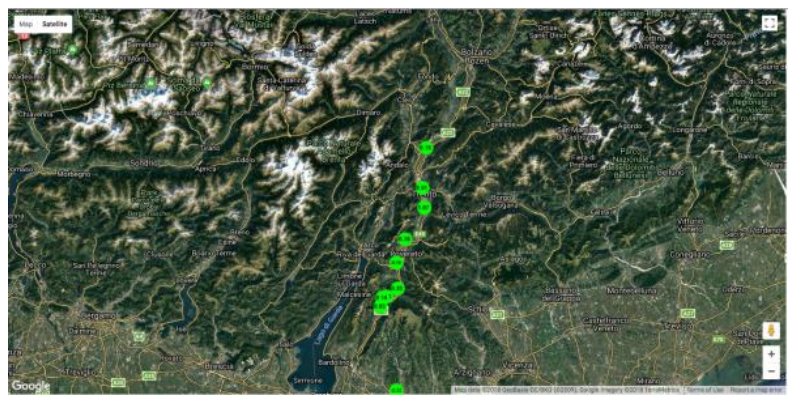

Figure 1: The River Adige sensor network as it appears on the open data web portal.

For the purpose of the installation, the author chose the centric station of the San Lorenzo bridge (in Trento City centre) and two independent data sets: flow rate and hydrometer. The sets covered the measurements of five days, at a rate of one measurement every fifteen minutes. The reasons for limiting the data to five days of history are to be found in the sound design choices and are explained in the following paragraphs.

\subsection{Sonification as a User - Centred Design Process}

Taking the risk of being over-reductive and for the sole purpose of this paper, we identified two main approaches to data sonification, both inside the academia and in the art practice world. From one side, we have what we will call a generative approach: sounds are synthesized algorithmically by purposely designed software; the translation from numerical data to sound is based on pre-determined parameters which associate certain values of the data set to certain elements of the sound material (amplitude, frequency, timbre, morphology). The objective of such projects is the 
scientific translation of quantitative information into an auditory experience, be it for analytical exploration or synthetic representation of data. The resulting soundtrack is usually streamed either offline or online and listened to via a headphone set, with notable exceptions (for instance, the Sonification Festival where projects were performed live in Berlin in late 2017). The second approach, though still generative by nature, has the objective of obtaining musical compositions from data sets, often performed with physical instruments in a performative setting. The process involved in this second case will be that of composing with the support of a traditional, written score to be handed out to the performer (for instance, the composition "The sound of climate change from the Amazon to the Arctic" by D. Crawford and S. St George for string quartet).

We propose here a third approach that we call designdriven and user-centred [25]. The accent of the sonification process is thus on the design of a sound experience that has at the core the user herself and the context in which she will listen to the sounds. We believe that sound is always heard, or listened to, in combination with other sensory modalities [26] and their respective inputs. Far from being a limitation, this is an opportunity to use sound to design meaningful, integrated and rich user experiences. In a traditional perspective that sees academia reflecting mainly on utility and functionality as main criteria to evaluate data sonification, the design perspective focuses on (paraphrasing G. Judelman) an aesthetic, though rigorous approach to the representation of numerical information [27]. We define here "aesthetic" not as a romanticised, subjective sense of beauty but as a design rationale conceptually analogous to that of traditional product design, architecture, or art [28].

\subsubsection{Choice of sound material}

In "SonifEye: Sonification of Visual Information using Physical Modeling Sound Synthesis" [23], Roodaki and colleagues purposely design the sounds elements to resemble sounds generated by natural phenomena, thus leading to an intuitive, therefore less tiring and stressful, processing of the auditory information. This attribute of sound is used to avoid alarm fatigue (a well-documented problem where professionals exposed to too many monitoring systems end up ignoring them in order to avoid perceptual stress, with clear decreased safety consequences [29]) and allow the visual channel to focus on other tasks, specifically high precision medical tasks conducted in a Virtual Reality training environment (such is the case in the SonifEye project). The aesthetic component of real time physical modelling sonification plays an important role leveraging sounds attribute that limit the cognitive effort needed to understand the underlying meaning of abstract sound material (and the information it carries) correctly.

In his "Audio-Vision: Sound at Cinema" [30], Michel Chion illustrates, through multiple examples derived from the history of the moving image, how sound is able to radically modify our perception of a movie narrative influencing the sense of time and space (synch point, spatial magnetization), overcoming the physical barriers of the screen (off-screen sound), and adding to the materiality of the image contributing to conveying tactile information such as speed and weight (materializing sound indices).

Cognitive sciences have added, in recent years, several elements that can be taken into account while designing sounds in a multi-modal setting. Prof. Charles Spence and his Cross -
Modal Interaction Lab at Oxford University have been investigating how the feeling of taste, colours, and sizes is influenced or can be stimulated by specific characteristics of auditory inputs such as pitch, rhythm, timbre. For example, people seem to consistently match high-pitched sounds with small, bright objects located high up in space [31] or lowpitched sounds with bitter taste [32]. Cross modal correspondences involving the auditory channel and other sensory modalities have by now been proven by a large body of research [31] and can be integrated in a design-driven approach to sonification.

All these elements were taken into account for the design of the sound material of the sonification process, in particular for the design of texture and morphology of sounds. Paraphrasing Michel Chion [30] we call this approach embodied sonification, i.e., an approach that focuses on the relationship between sounds and the listening experience, mediated by elements borrowed from other sensory modalities, like sight (objects, images, moving images); smell (food); touch (objects, food); taste (food). In this perspective, the design of each sound element is the result of a research on texture, timbre, and in general the matter of sound in order to suggest or amplify such a relationship.

We cannot not mention the work of Stephen Roddy on Embodied Sonification [33] which utterly resonates with the approach we have taken for Res Extensae. We too, with Roddy, believe that "Embodied cognition is defined by how it answers the age-old mind-body problem, the question of how the human mind relates to physical matter" and that this approach can help to bridge the "Cartesian divide" offering a "truly cohesive account of auditory meaning-making" [6].

An investigation of the cognitive and philosophical framework of embodied cognition exceeds the scope of this paper but it sits at the background of every decision we took owing much to the work of the Chilean philosopher Francisco Varela and his "The embodied mind" [34].

\subsection{Building the context. Found objects and narrative}

The quest for a data humanism [35], an approach to data design that goes beyond a merely technical relationship with the data representation and towards the story behind data itself, calls for posing the accent of data representation on the larger context. In the current perspective of sonification, where, as already noted, acousmatic sounds are mainly predominant, physical objects can play the role of mediators [36], reinforcing the narrative and embodying the acousmatic sounds into a res extensa. The subjective, often intimate relationship of an individual with the materiality and physicality of objects is part of what "authenticity can be defined by - the subjective experience through which the physicality of an object can elicit experiential, meaningful, and affective responses" [21].

In the Found Object Project, an extensive study on our relationship to objects we happen to find by various means by Paul M. Camic, personal attachment to everyday object is described as the resultant of a cognitive process involving "the interaction of aesthetic, cognitive, emotive, mnemonic, ecological, and creative factors" [37]. As Donald Norman puts it, though, our attachment is not to the thing, it is to the relationship, to the meaning and feelings the thing represents [10].

The use of acousmatic sounds deprives the user from such a meaningful relationship. We argue that the lack of the 
physical element negatively affects the appreciation of the context and the interpretation of the auditory element as part of a narrative, making it more difficult for the listener to engage with data in a meaningful way. For Res Extensae, we decided to include in the listening experience a few found objects (five, each representing one day of data), with the goal of evaluating the impact of the physical element on the overall user experience and on the comprehension of the context and its narrative.

\subsubsection{Reinforcing the narrative: objects as sonic boards}

As we already mentioned, the way sound is broadcasted and therefore experienced by the final user is sometimes quoted as a disincentive to the affirmation of a sonification field [16]. For this reason, and to reinforce the relationship with the found objects as a background canvas for locating sounds in a context, we decided to use audio transducers instead of traditional speakers. Transducers where placed inside (or under) each object so that the sound material would come out of the object itself, inviting the users to get closer to it and facilitate what Csikszentmihalyi calls a "flow experience" [38].

\section{WORK PROCESS}

\subsection{Sonification process}

The initial sound material was synthesised using proprietary software by Native Instruments ${ }^{\circledR}$ (NI). Having to deal with two different data sets (flow rate and data from hydrometer at a given sensors station) we identified two different sounds connected to data by two different rules, and we approached these two aspects differently in terms of work process. Being, as we will see, the whole process manual, we were obliged to select a human scale set of data, limiting it to five days in the life of the river, with one data input every fifteen minutes, for each set (flow rate and hydrometer). It is obviously a fundamental limitation in the sonification process and we will get back to this issue in the conclusions of this paper.

\subsubsection{Hydrometer}

For the data set relative to the hydrometer, which measures the river height at a given point, identification of the mapping rules came first. In particular, we chose one of the most common sonification association [19], i.e., the representation of height values as pitch values, but we applied this criterion loosely giving priority to aesthetic rules. In other words, we twisted the concept of a direct translation of height numerical values into frequency numerical values, in order to obtain an increased variety of texture and richness of the sound samples.

The need for an increased variety emerged while analysing the data set. Undeniably, measurements taken within fifteen minutes are, under normal circumstances, most likely to be very similar, giving as a result a monotonous sound experience. We therefore applied a mixed parametrisation, splitting the numerical value in two parts and using the resulting parts to program two distinct synthesizers. The sound sample associated with each data was a resultant of this combination, applied to a customised patch of the software Absynth ${ }^{\circledR} 5$ by NI. For example, the starting height of $102 \mathrm{~cm}$ on Day 1, time 00:15 was translated into a sound combining an Oscillator (A) at a frequency of $10,000 \mathrm{~Hz}$ and an Oscillator (C) at a frequency of $2,000 \mathrm{~Hz}$. A third Oscillator (B) was kept by default at the frequency of $-2.000 \mathrm{~Hz}$. The choice of timbre took into consideration the intrinsic melodic nature of a soundtrack resulting from the association between a numerical value and a frequency.

In the context of a design approach, we proceeded manually recording sound by sound (one sound for each single numerical data), before moving to the editing software (Steinberg Nuendo® 5) for montage and post-production. This approach conceptually followed the idea of using sonification to convey analytical information to the listener.

\subsubsection{Flow Rate}

For the flow rate, we experimented with the sound texture trying to keep a "natural" connection with the data itself [19] with the intention of triggering an intuitive apprehension of the context of origin of the data represented [17]. In this sense, this second approach conceptually followed the idea of using sonification to convey synthetic information (a bird's eye view) on the overall status of the river [23]. The initial sound material was synthesised using NI Reaktor ${ }^{\circledR} 6$ looking for a texture that could aurally mimic the feeling of an underwater current. The mapping of this complex sound element to the single elements of the data set was done manually, loosely associating each numerical value to the position of the cursor on the sample while recording the whole process in real time. The idea being that the abrupt changes in the sample formant provoked by this process would have been intuitively perceived as changes in the river current's energy. The entire data set was performed, manually scrolling the cursor along the timeline. The performance was recorded in real time and subsequently imported into Steinberg Nuendo® 5 for postproduction.

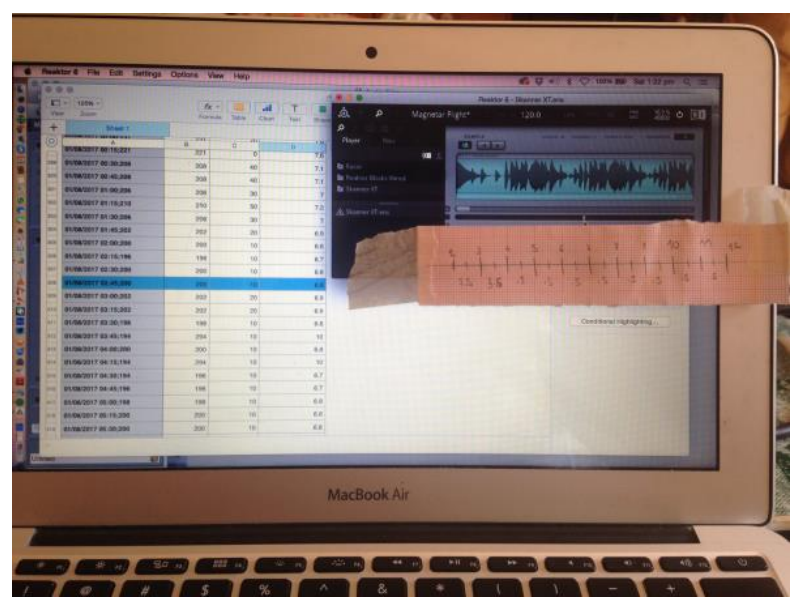

Figure 2: Real time performance and recording process of the flow rate data set.

\subsection{Choice of objects}

Each object was hand-picked in the area of Trento, and chosen among those objects of the local tradition which used to or still do contain water, or liquids. The idea behind, quite simply, 
was connecting data, sounds and objects within the same narrative, focussing around the same topic, the river. We expected this process to enhance the memorability of the experience and to facilitate the intuitive appreciation of the data sets through the embodiment of sounds in the physical dimension of the objects.

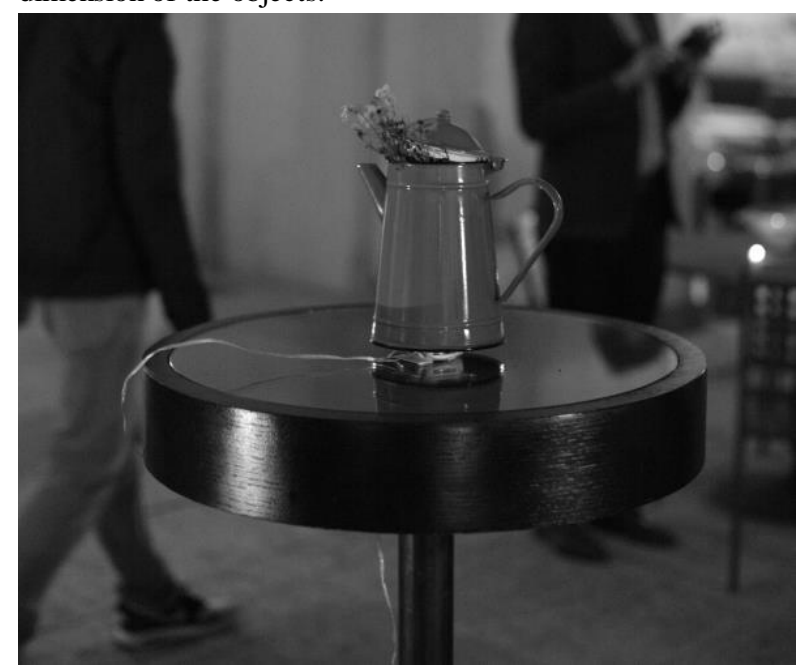

Figure 3: One of the found objects with sound transducer used for the project.

\subsection{The installation}

The exhibition space consisted in an outdoor area of circa fifty square meters. The objects were placed on supports (one support per object) and located in the space for guests to encounter them on their path. As mentioned, each object also functioned as the sound source thanks to the audio transducers. Each object was labeled with the data set it played and the day it referred to, in a way that reminded that of natural science museums' display of items, thus encouraging the public to get near the object for close observation (in this case, for close listening). The event took place at night in a low-light setting. Each object had its own LED source of light to amplify, once again, the focus on the sound source.

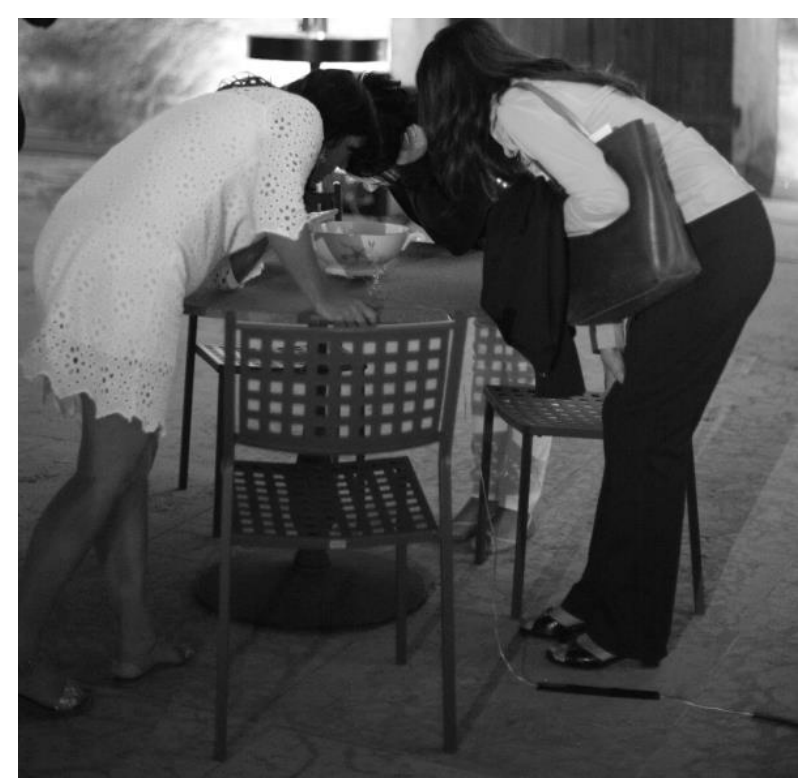

Figure 4: One of the objects and sound stations during the installation.

\section{TESTING WITH USERS}

Six months after the event, a ten questions survey was emailed to thirty selected participants. The selection was made based on several factors including country of residence (in order to have the highest possible variety of cultures) and possibility of reach (there was not an official list of participants except those belonging to the delegations of the OSIRIS project or personally invited by the author). Of the 30 surveys sent out, 15 came back for inclusion in this paper. The response rate was therefore of $50 \%$. The questionnaire was easily accessible via SurveyMonkey.com The following paragraphs highlight the most relevant aspects of questions and answers, for further discussion. Question 10 is excluded from this report because of its vague formulation that led to unclear/unusable results; Question 9 asked to quote three keywords describing the work: the result, though very interesting for the author, is not deemed to be relevant for the present discussion.

\subsection{Efficacy of sonification}

The first question addressed the main objective of Res Extensae and asked to participants to express with a Yes/No answer whether they felt sound could be an effective means of communicating the value and the potentialities of public administration data sets. $86.67 \%$ of the users answered positively. This group subsequently rated $62 \%$ (Question 2) the efficacy of sound as a means of communicating the value of data, on a scale from 1 (lowest value) to 100 (highest value).

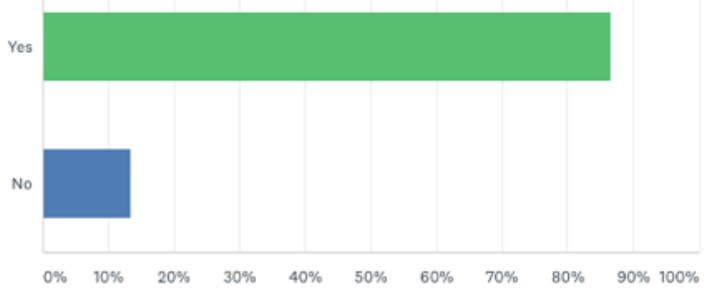

Figure 5: Question 1, results.

\subsection{Influence of the objects on the experience}

More relevantly for the present work, the association between sounds and physical objects during the experience was clearly perceived as a relevant added value to the sound experience by the totality of the respondents. 


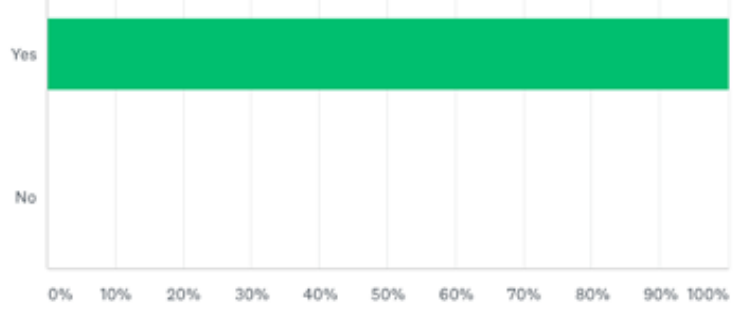

Figure 6: Question 4, results.

The meaning of "added value" was subsequently defined as: suggesting a context for the data sets $(60 \%)$, creating an emotional connection with the sound (53.55\%), building a narrative, attracting attention, and enhancing memorability (46.67\%); amplifying the sound experience and creating an emotional connection with the data set $(26.67 \%)$.

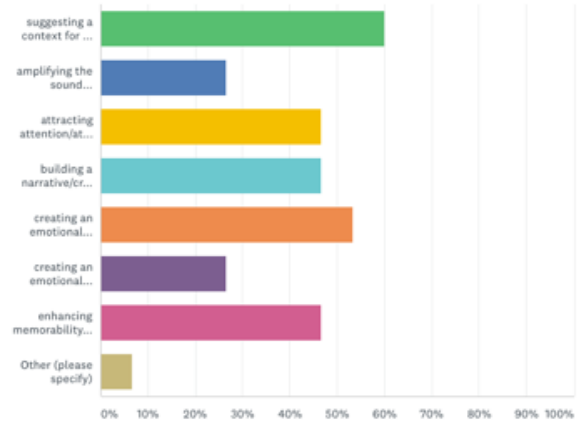

Figure 7: Question 4, results.

Interestingly, the capability of sound to engage the listeners seems to lose more than half of its power when sonification is experienced without the object. Asked to relisten to the sonification through headphones, without the physical presence of the object, the engagement was given a rate of 48 on a scale of 100 , where 100 was the engagement of the sonification with the object.

\subsection{Sound as a humanizing factor in data representation}

Asked whether, after the experience, they would consider sound as a humanising factor in the representation of quantitative data set, i.e., able to make numerical data less abstract and closer to our everyday experience, the majority of users answered positively (71.43\%)

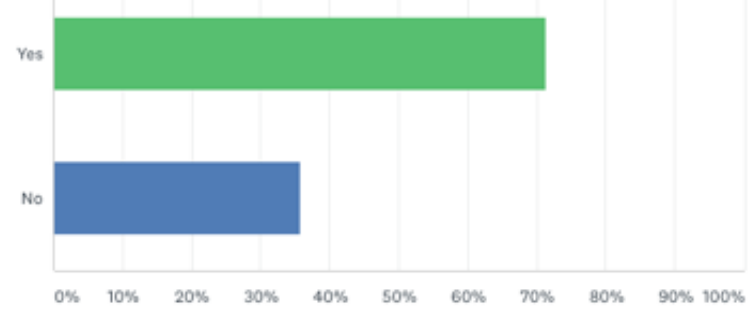

Figure 8: Question 7, results.
The "humanising" power of sound was given an overall value of 59 on a scale of 1 (lowest value) to 100 (highest value).

\subsection{Targets of sonification}

Question 3 asked the participants to select target groups which they thought could most benefit from the use of sound to represent data. Media was the most relevant group according to the participants $(66.67 \%)$, followed by researchers and scientists $(60 \%)$, students $(53.33 \%)$ and citizens $(46.67 \%)$. "Other" $(26.67 \%)$ included a suggested target group defined by its relationship with the arts (suggestions included art institution, cultural institutions, artists).

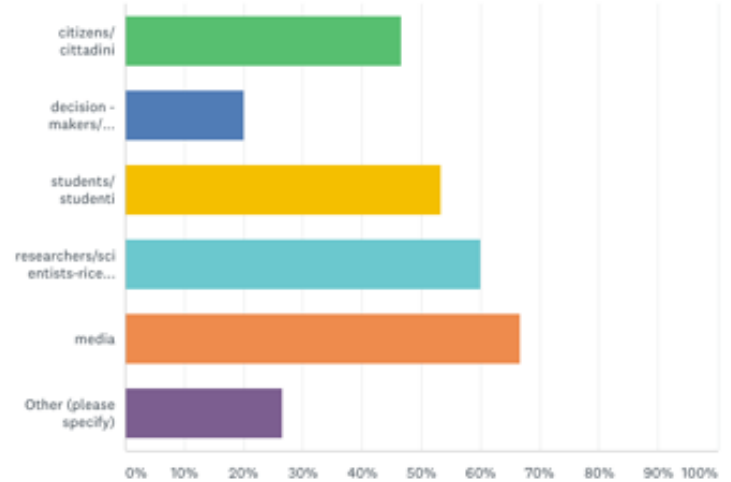

Figure 9: Question 3, results.

\subsection{Discussion}

For most, if not all, of the participants the event described in this work was the first encounter with the field of data sonification. It is therefore particularly encouraging to note that the majority of the participants considered sound as a valuable means to convey the meaning of the data set. "Valuable" is here intentionally used as a broad term meant to indicate a positive feeling towards the importance of communicating public administration data to a wider public which was, as explained earlier in this work, one of the main interests of the project's stakeholders.

Quite surprisingly, given the artistic nature of the work, the respondents indicated "Researchers and Scientists" as one of the categories which would most benefit, in their opinion, of the usage of sound to represent data.

There is no doubt that the presence of physical objects facilitated the overall experience conveying, as we hoped, an increased sense of context to the data sets and creating an emotional connection with it. Enhancing memorability, building a narrative and attracting attention are other aspects of embodied sonification which seem to be promising. The objects seem to function as catalysts for an increased understanding and improved relationship with the sounds representing the data sets. It seems reasonable to hypothesize that physical objects are able to balance the acousmatic relationship grounding it in a physical context

\section{CONCLUSIONS AND FUTURE DEVELOPMENTS}

This paper presents a seminal work in a design-driven, user-centred approach to data sonification. In particular, we introduce the usage of physical objects in association with sounds, where sound represents the actual data sets and objects help the users to put sounds and data into a wider 
context, improving the user experience and facilitating the comprehension and retention of the meaning of data. This multi-modal approach to the design of data experiences seems, despite the small number of respondents to the testing phase, promising. We also believe that this approach, if validated, could be of interest for the development of Virtual Reality environments for data representation with an embodied approach to sonification.

Further development will investigate the role of sound material which is "naturally" connected to the meaning of the data they represent. Experiments will be carried out with different sound matter including speech and soundscape, and leveraging the potentialities of physical synthesis.

\subsection{Limits of the present approach}

The manual approach to data sonification that this project has presented, justified by the author's interest in design practices, presents an evident limitation in the amount of sounds that can be created and therefore the amount of data that can be analysed and represented. Further developments will investigate how to automatize the approach, including in realtime sonification.

\section{ACKNOWLEDGMENT}

Sara Lenzi wishes to thank the INTERREG Europe OSIRIS program, Trentino Open Data and the Provincia Autonoma di Trento, Servizio Supporto alla Direzione Generale e ICT (Cristiana Pretto) for taking the risk to sponsor an-out-of-thebox project; the Trento Chamber of Commerce for hosting the installation in the beautiful space of Palazzo Roccabruna; $\mathrm{Mr}$ Bruno Lorengo of the Ufficio Dighe - Servizio Prevenzione Rischi for his help in organising the data sets on a human scale; Prof. Paolo Ceccarelli from Density Design Lab, Politecnico di Milano (Italy) and Prof. Lonce Wyse, National University of Singapore, for their precious feedback on this paper.

\section{REFERENCES}

[1] Communication from the Commission of the European Parliament, "Open data. An engine for innovation, growth and transparent governance", COM (2011) 882 Final, Brussels, Belgium, 2011.

[2] É. Bassot and W. Hiller, "Key Policy Challenges for the EU in 2017 EPRS", European Parliamentary Research Service, 2016.

[3] W. Carrara, W. San Chan, S. Fischer and E. van Steenbergen, Creating Value through Open Data: Study on the Impact of Re-use of Public Data Resources, European Union, 2015.

[4] Communication from the Commission of the European Parliament, "A Digital Single Market for Europe COM(2015) 192 Final, Brussels, Belgium, 2015.

[5] https://www.dati.gov.it/content/disponibile-registrazionewebinar-ruolo-caratteristiche-portale-europeo-dei-dati (Last access 15th Feb 2018).

[6] S. Roddy and D. Furlong, "Sonification listening: an empirical embodied approach", in Proc of the $21^{\text {st }}$ International Conference on Auditory Display (ICAD), pp. 181-187, Graz, Austria, 2015.

[7] Data Visualisation Project, Google Trends, available at https://trends.google.com/trends/story/US_cu_6fXtAFIB AABWdM_en) (Last access 10th May 2017).
[8] S. Rogers, Data needs empathy to make it real, Google News Lab, 2017. Available at https://medium.com/google-news-lab/data-needsempathy-to-make-it-real-c9ca0f0aea6d (Last access 10th May 2017).

[9] J. Harris, Connecting with the dots, 2015. [online] https://source.opennews.org/articles/connecting-dots/ (Last access: 10th May 2017).

[10] D. Norman, Emotional Design: Why We Love (or Hate) Everyday Things, New York, U.S.: Basic Books, 2005.

[11] N. Cawthon and A. Vande Moere, "The Effect of Aesthetic on the Usability of Data Visualisation", in Proc of the 11th International Conference on Information Visualisation, Zurich, Switzerland, 2007.

[12] http://data-cuisine.net/

[13] http://alicethudt.de/

[14] https://www.adriensegal.com/

[15] N. Rönnberg, J. Löwgren, "The Sound Challenge to Visualization Design Research", in Proc of EmoVis, ACM IUI Workshop on Emotion and Visualization, Sonoma, CA, USA, 2016.

[16] C. Dayé and A. de Campo, "Sounds sequential: sonification in the social sciences", Interdisciplinary Science Reviews, Vol. 31, N. 4, 2006.

[17] B. Rau, F. Friess, M. Krone, C. Muller and T. Ertl, "Enhancing visualization of molecular simulations using sonification", in Proc of 1st International Workshop on Virtual and Augmented Reality for Molecular Science (VARMS@IEEEVR), 2015.

[18] A. de Campo, C. Dayé, C. Frauenberger, K. Vogt, A. Wallisch and G. Eckel, "Sonification as an interdisciplinary work in progress", in Proceedings of the 12th International Conference on Auditory Display, London, UK, 2006.

[19] C. Scaletti, A.B. Craig, "Using sound to extract meaning from complex data", in SPIE Vol. 1459 Proc of Electronic Imaging '91, San Jose', California, U.S., 1991.

[20] P. Schaffer, Traité des objets musicaux, Paris, France: Le Seuil,1966.

[21] Varnalis-Weigle, Anastasia S. "A Comparative Study of User Experience between Physical Objects and their Digital Surrogates", Journal of Contemporary Archival Studies, Vol. 3, Article 3, 2016.

[22] G. Kramer, B. Walker, T. Bonebright, P. Cook, J. H. Flowers Sonification Report: Status of the Field and Research Agenda, 2010.

[23] H. Roodaki, N. Navab, A. Eslami, C. Stapleton, and N. Navab, "SonifEye: Sonification of Visual Information using Physical Modelling Sound Synthesis", IEEE Transactions on Viz and Computer Graphics, vol. 23 No. 11, Nov 2017.

[24] https://www.interregeurope.eu/osiris/

[25] D. A. Norman, S. W. Draper User Centered System Design; New Perspectives on Human-Computer Interaction, Boca Raton, Florida, U.S.: CRC Press, 1986.

[26] P.M. Lindborg, Sound perception and design in multimodal environments, Doctoral Thesis, KTH Royal Institute of Technology, Stockholm, Sweden, Dec 2015.

[27] G. Judelman, "Aesthetic and Inspiration for Visualization Design: Bridging the Gap between Art and Science", in Proc the Eighth International Conference on Information Visualisation (IV'04), London, UK, 2004. 
[28] A. Calvera, "Nulla ethica sine aesthetica: should aestheticism still be stigmatized?", Utopia. The Radical Designist, Dec 2016.

[29] S. Sendelbach and M. Funk, "Alarm fatigue: a patient safety concern", in AACN Advanced Critical Care, 24(4):378-86, Oct 2013.

[30] M. Chion, Audiovision: Sound on Screen, New York, U.S.: Columbia University Press, 1994.

[31] C. Spence, "Crossmodal correspondences: A tutorial review”, Attention Perception Psychophysics 73:971995, May 2011.

[32] A. S. Crisinel, C. Spence, "As bitter as a trombone: synesthetic correspondences in non-synesthetes between tastes/flavors and musical notes.", Attention Perception Psychophysics 72(7):1994-2002, Oct 2010.

[33] S. Roddy, Embodied Sonification, Doctor of Philosophy Thesis, University of Dublin, Ireland: Trinity College, 2015.

[34] F. J. Varela, E. Thompson and E. Rosch, The Embodied Mind. Cognitive Science and Human Experience, Cambridge, Massachusetts, U.S.: The MIT Press, 1993.

[35] G. Lupi, "We reached peak infographics. Are you ready for what comes next?", 2017. [online] Available at: http://www.printmag.com/information-design/datahumanism-future-of-data-visualization/ (Last access: 10th May 2017).

[36] S. Sato, M, Takahashi and M. Matsuo, "Giving Context to Sounds through Mediation of Physical Objects", in Proc of UbiComp, Zurich, Switzerland, Sept 2013.

[37] P. M. Camic, "From Trashed to Treasured: A Grounded Theory Analysis of the Found Object", Psychology of Aesthetics, Creativity, and the Arts, Vol. 4, No. 2, pp. 81-92, Oct 2010.

[38] M. Csikszentmihalyi Flow: The psychology of optimal experience, New York, U.S.: Harper \& Row, 1990. 